\title{
Ageing effects on phase transformations in NiTi alloys
}

\author{
K. K. Mahesh, F. M. Braz Fernandes ${ }^{\mathrm{a}}$ and Rui J. C. Silva \\ CENIMAT/I3N, Faculdade de Ciências e Tecnologia (FCT), UNL, 2829-516 - Monte de Caparica, Portugal
}

\begin{abstract}
Phase transformation behaviour of Ti-rich and Ni-rich NiTi SMAs subjected to two rounds of heat treatments are compared. The first group of samples, received as straight-annealed, was subjected to a series of heat treatments in the temperature range from 200 to $900^{\circ} \mathrm{C}$ (designated in the text as 1 st round of heat treatments). A second group of samples was subjected to a previous annealing at $900^{\circ} \mathrm{C}$, followed by heat treatments in the temperature range from 200 to $900^{\circ} \mathrm{C}$ (designated in the text as 2 nd round of heat treatments). Phase transformation temperatures are determined by electrical resistivity (ER) measurement in the temperature range from -140 to $+130^{\circ} \mathrm{C}$. It was observed that Ti-rich NiTi alloy, previously annealed at $900^{\circ} \mathrm{C}$ during the 1 st round of heat treatments, does not show any change in transformation characteristics after the 2 nd round of ageing treatments, whereas, for $\mathrm{Ni}$ rich NiTi alloy, it was found that there is a difference in the transformation behaviour after the 2 nd round of ageing treatments.
\end{abstract}

\section{Introduction}

SMAs are acquiring much demand in various application fields due to their shape recovery and superelastic properties. There are several alloy systems that exhibit these properties and NiTi alloy system shows such properties at a higher level. Shape memory effect (SME) is caused by the thermoelastic reversible martensite phase transformation. In the case of NiTi SMAs, high temperature austenite phase has $\mathrm{CsCl}$ crystal structure, low temperature martensite phase has monoclinic structure and the intermediate phase has rhombohedral structure. Phase transformation temperatures have been found to depend upon a number of factors ranging from the chemical composition and preparation techniques to the thermal/mechanical treatments [1-3].

Heat treatment is found to be one of the simplest, most economic and best methods adopted for manipulating the transformation properties of SMAs. Perhaps, it has the widest reaching and important ramifications when compared to other stages in the fabrication of shape memory components and structures. Otsuka et al., adopted a heat-treatment in which they homogenised the Ni50at\%-Ti alloy for $1 \mathrm{hr}$ at $1000^{\circ} \mathrm{C}$ followed by furnace cooling so as to eliminate the vacancies and the disorder to some extent [4]. They found that quenched specimen has almost the same transformation temperatures as the furnace cooled one. Huang and Liu, have found that the annealing temperature strongly affects the transformation behaviour of superelastic Ti$50.85 \mathrm{Ni}(\mathrm{at} \%) \mathrm{SMA}$ [5]. It was previously found by that during heat-treatment, $\mathrm{M}_{\mathrm{s}}$ and mechanical behaviour of $\mathrm{Ni}$-rich off-stoichiometric $(>50.7 \mathrm{at} \% \mathrm{Ni}) \mathrm{NiTi}$ alloys were sensitive to cooling rate, whereas, near-stoichiometric $(50.4$ at $\% \mathrm{Ni})$ alloys were not [6]. Liu et al., studied the effect of low temperature ageing on the transformation behaviour in a near equi-atomic NiTi alloy and concluded that the precipitation induced by the ageing treatment is responsible for the unusual transformation behaviour [7]. It is recently showed that precipitation of $\mathrm{Ni}_{4} \mathrm{Ti}_{3}$ particles occurred in a matrix of Ni-rich NiTi SMA, when it was solution annealed at $850^{\circ} \mathrm{C}$ for 15 minutes followed by water quenching and ageing at $400^{\circ} \mathrm{C}$ for $20 \mathrm{hrs}$ [8]. Uchil et.al., have studied the effect of heat treatments on phase transformation temperatures of NiTi alloys of various compositions [2,9]. In a more recent study, transformation behaviour of different heat treated NiTi and NiTiCr alloys employing quenching and furnace cooling were investigated [10].

In the present work, Ti-rich and Ni-rich NiTi SMAs were subjected to two rounds of heat treatments between $200^{\circ}$ and $900^{\circ} \mathrm{C}$. Phase transformation behaviour was studied by electrical resistivity (ER) measurement in the temperature range from -130 to $+140^{\circ} \mathrm{C}$. The results are discussed in the context of effect of composition on the ageing process in these alloys.

\footnotetext{
a e-mail: fbfefct.unl.pt
}

This is an Open Access article distributed under the terms of the Creative Commons Attribution-Noncommercial License (http://creativecommons.org/licenses/by-nc/3.0/), which permits unrestricted use, distribution, and reproduction in any noncommercial medium, provided the original work is properly cited. 


\section{Experimental procedure}

Alloy systems comprising of two compositions, viz., Ni49.5at\%-Ti (Ti-rich NiTi) and Ni51.0at\%-Ti (Ni-rich $\mathrm{NiTi}$ ) in the wire form of diameters $0.636 \mathrm{~mm}$ and $2.11 \mathrm{~mm}$, respectively were obtained from Memory-Metalle $\mathrm{GmbH}$, Germany. The as-received (AR) wires were straight annealed and having active $\mathrm{A}_{\mathrm{f}}$ temperatures of $74^{\circ} \mathrm{C}$ and $35^{\circ} \mathrm{C}$, respectively. Heat treatments were performed in two rounds. In the first round, the AR wires (in the condition of straight-annealed) of about $50 \mathrm{~mm}$ long were taken and annealed at different temperatures between $200^{\circ}$ and $900^{\circ} \mathrm{C}$ for 20 minutes in a muffle furnace and thereafter suddenly quenched to room temperature by dropping it to a water bath. After the annealing, ER measurements during temperature variation were carried out by employing four-probe electrical resistivity technique. In the second round, the specimen annealed at $900^{\circ} \mathrm{C}$ was heat treated at desired temperatures in the range from 200 to $900^{\circ} \mathrm{C}$ for 20 minutes and again the ER measurements were performed so as to obtain the phase transformation temperatures. Each time, before loading the sample to the ER equipment, care was taken so as to remove the oxide layer from the wire surface by subjecting it to chemical etching $\left(10 \%\right.$ vol. $\mathrm{HF}+45 \%$ vol. $\mathrm{HNO}_{3}+45 \%$ vol. $\left.\mathrm{H}_{2} \mathrm{O}\right)$ for ensuring proper electrical contacts.

Temperature variation of ER was carried out using home-made four-probe equipment. Four-probe setup encapsulated in a metal cylinder wound with the heating coil was kept inside the larger outer metal cylinder containing liquid nitrogen. Cooling rate is controlled by adjusting the level of liquid nitrogen in the outer cylinder and a lowest temperature of $-130^{\circ} \mathrm{C}$ could be easily obtained. In order to warm and come up to room temperature, liquid nitrogen is drained from the chamber. To heat from room temperature up to $+140^{\circ} \mathrm{C}$, electric current in the heating coil was adjusted by making use of the power regulator. Temperature of the specimen was measured by means of a chromel-alumel thermocouple. For the four-probe set-up, the constant current was supplied with Agilent System DC power supply (N5748A) and the voltage was interfaced with the PC via National Instrument circuit board (ASSY183364C-01) associated to the Virtual bench logger interface software. ER (a.u.) versus Temperature profiles were obtained in order to compare the transformation characteristics of the samples after heat treatments.

\section{Results and discussion}

\subsection{First round of heat treatments}

First round of heat treatment on these alloy systems was found to have a distinct effect on the transformation characteristics. In Fig. 1(a), while heating, the ER increases continuously until the temperature reaches $71^{\circ} \mathrm{C}$. On further heating, the rate of increase of ER increases indicating the start of transformation to austenite. Above $75^{\circ} \mathrm{C}$, the rate of increase of ER decreases, indicating the finish of transformation to austenite. The resulting transformation sequence is $\mathrm{M} \rightarrow \mathrm{A}$. While cooling from the austenite phase, the ER decreases until $75^{\circ} \mathrm{C}$ and, below this temperature, starts increasing gradually, followed by abrupt increase representing the start of transformation to R-phase. The rate of increase of ER decreases below $50^{\circ} \mathrm{C}$, representing the finish of transformation to R-phase. Further cooling below $31^{\circ} \mathrm{C}$, the ER decreases abruptly representing the start of transformation to martensite and the slope of the curve decreases until the temperature reaches $16^{\circ} \mathrm{C}$, indicating the finish of transformation to martensite. This behaviour gives rise to the 'cap' shape to the ER curve showing $\mathrm{A} \rightarrow \mathrm{R} \rightarrow \mathrm{M}$ phase transformation while cooling. The 'cap' shape of ER curve suggests the presence of R-phase in the transformation sequence. This behaviour persists even after ageing at $500^{\circ} \mathrm{C}$. As the ageing temperature is increased, transformation temperatures also increase. Further heat treating in the temperature range from 520 to $900^{\circ} \mathrm{C}$ resulted in R-phase transformation being absent and one-stage phase transformation $\mathrm{M} \leftrightarrow \mathrm{A}$ present both while heating and cooling. In the case of Ni-rich alloy, AR specimen possesses $M \leftrightarrow R \leftrightarrow A$ phase transformations while heating and cooling. However, while cooling M-phase transformation was not complete. By subjecting the alloy to heat treatment, the transformation temperatures increased and the temperature range of the R-phase 'cap' in ER curves gets narrower. For the sample aged at $640^{\circ} \mathrm{C}$, while heating, only $\mathrm{M} \rightarrow \mathrm{A}$ phase transformation and, while cooling, $\mathrm{A} \rightarrow \mathrm{R} \rightarrow \mathrm{M}$ phase transformations were observed. Further, annealing at higher temperatures up to $900^{\circ} \mathrm{C}, \mathrm{R}$-phase transformation was also observed while heating. 
(a) AR

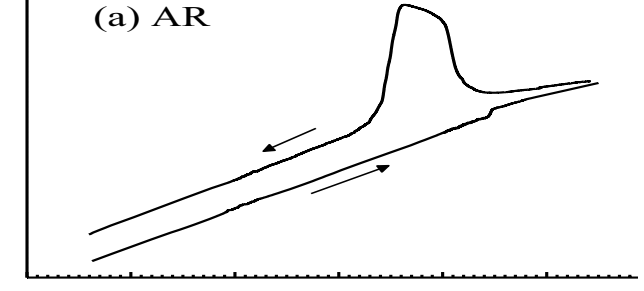

(b) HTT400

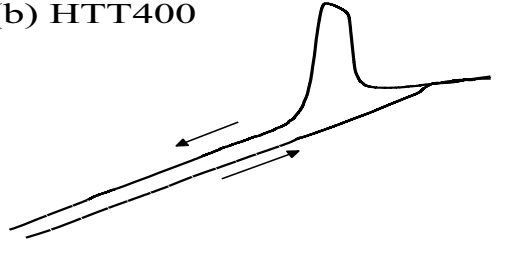

(c) HTT480

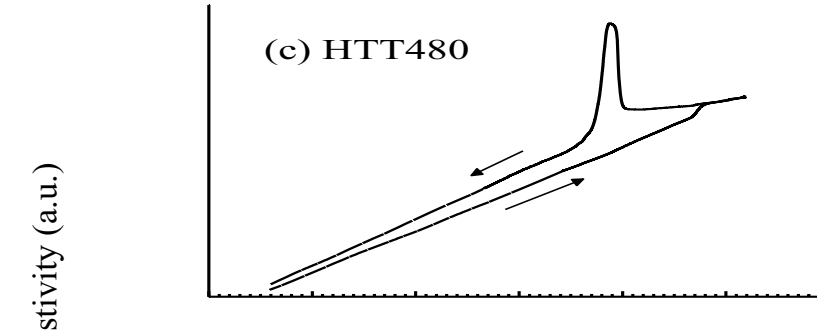

(d) HТT500

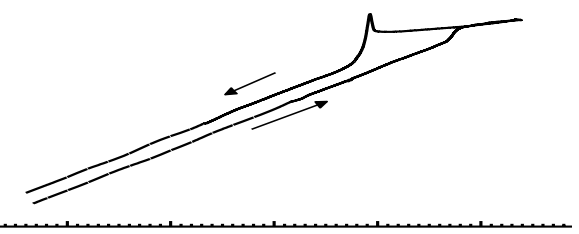

(e) НTт520
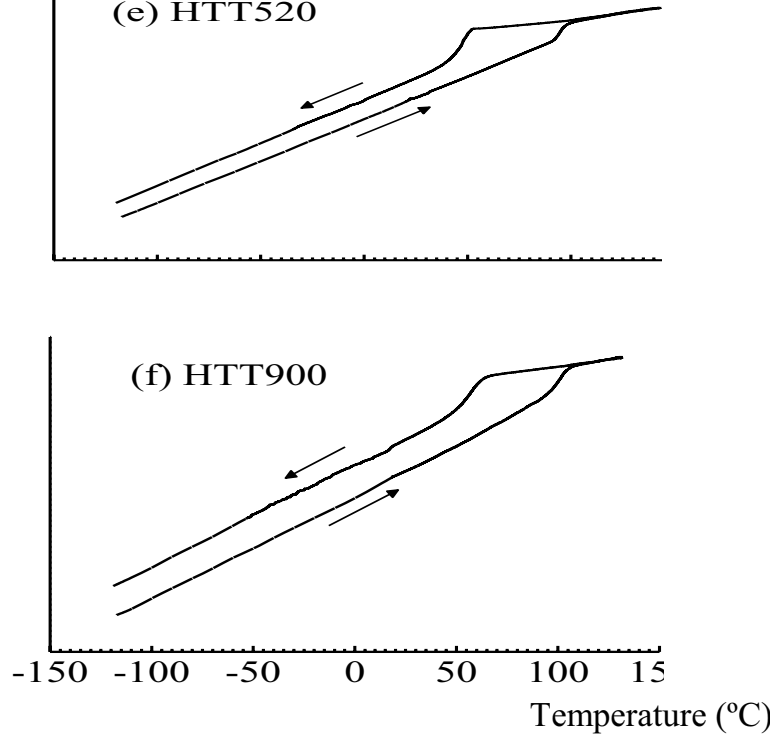

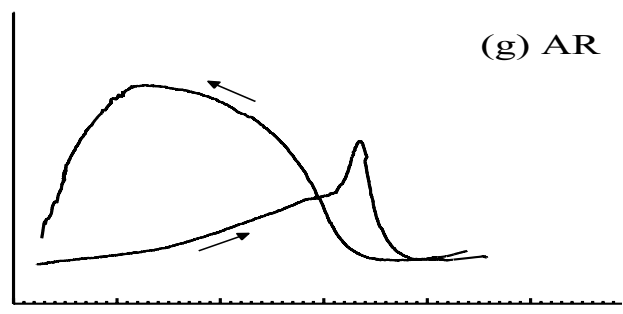

(h) HТT500

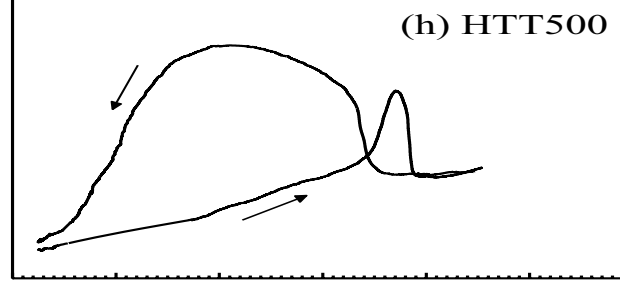

(i) HTT580

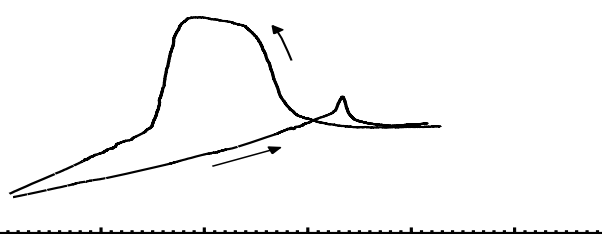

(j) НТT640

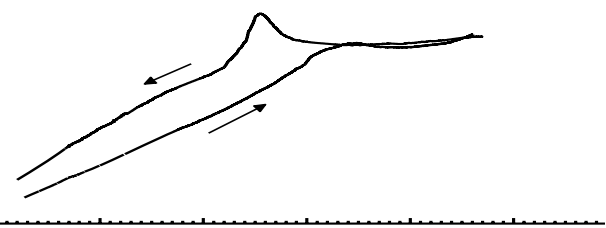

(k) НТТ720

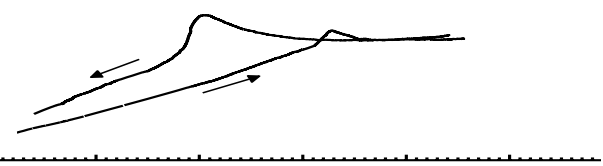

(1) НТT900

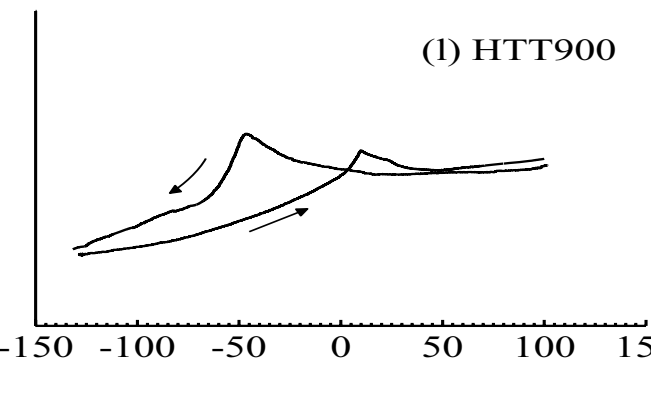

Fig.1: ER curves of the Ti-rich NiTi alloys (a-f) in AR and after 1st round HTT conditions at 400, 480, 500, 520 and $900^{\circ} \mathrm{C}$, and Ni-rich NiTi alloys (g-l) in AR and 1st round HTT conditions at 500, 580, 640, 720 and $900^{\circ} \mathrm{C}$. 


\subsection{Second round of heat treatments}

After the second round of heat treatments preceded by the annealing at $900^{\circ} \mathrm{C}$, Ti-rich and Ni-rich NiTi alloys show quite different behaviours. Fig. 2 depicts the ER profiles for the Ti-rich samples after the second round of heat treatments at $400,500,700$ and $900^{\circ} \mathrm{C}$. It may be noted that only $\mathrm{M} \leftrightarrow \mathrm{A}$ phase transformation behaviour is observed after heat treating in all the temperatures in the tested range. Intermediate R-phase transformation is absent. The observed behaviour is similar to that of the Ti-rich NiTi sample annealed at $900^{\circ} \mathrm{C}$, during the first round, as seen in Fig. 1(f). The transformation temperatures also remain fairly the same.
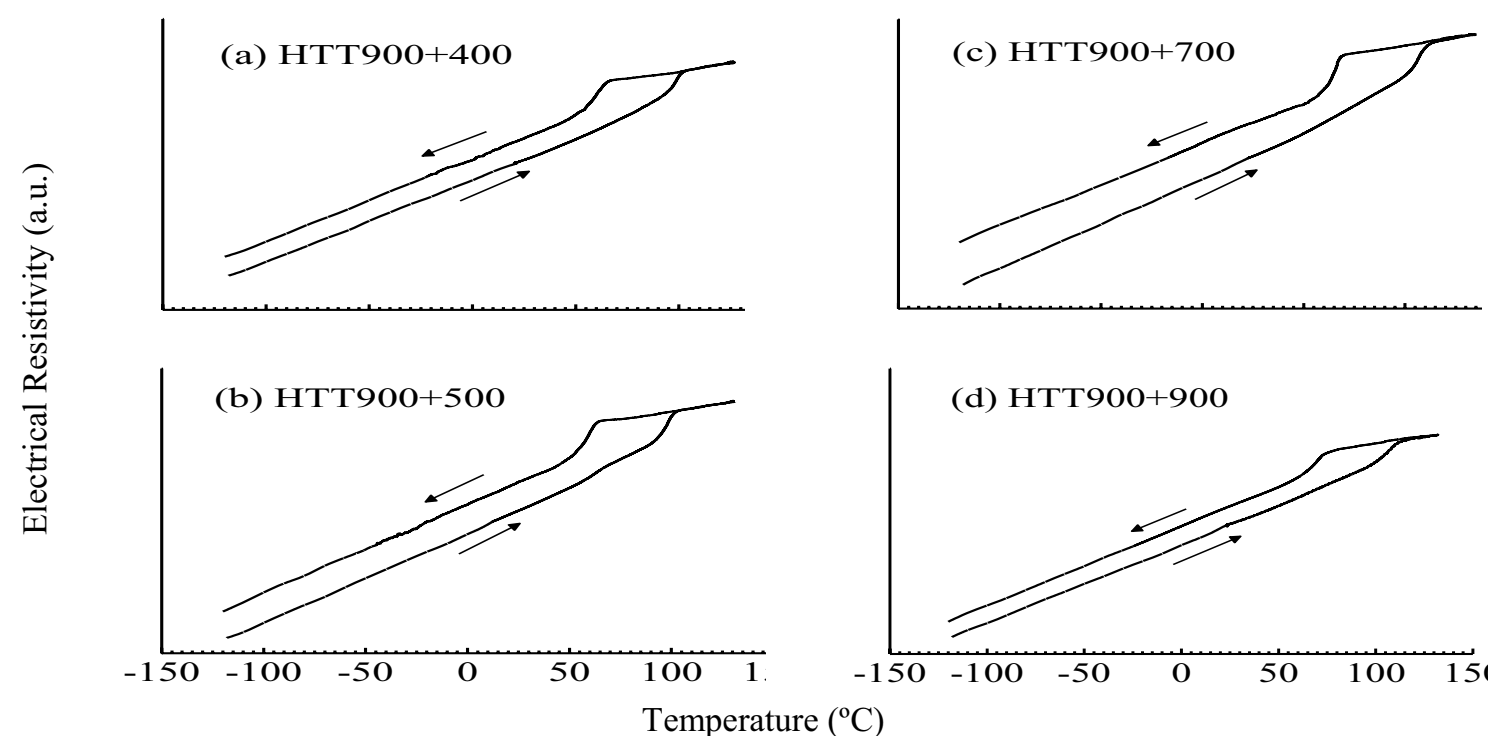

Fig.2: ER curves of the Ti-rich NiTi alloys previously annealed at $900^{\circ} \mathrm{C}$ followed by 2 nd round of heat treatments at (a) 400, (b) 500, (c) 700 and (d) $900^{\circ} \mathrm{C}$.

In Fig. 3, ER curves of the Ni-rich NiTi alloys previously annealed at $900^{\circ} \mathrm{C}$ followed by 2nd round of heat treatments at various temperatures are shown. ER curves for the sample aged at $200^{\circ} \mathrm{C}$ show similar behaviour to that of after the first annealing at $900^{\circ} \mathrm{C}$ as observed in Fig. 1(1). As the heat treatment temperature (HTT) was increased until $300^{\circ} \mathrm{C}, \mathrm{M}_{\mathrm{s}}$ decreased and the temperature interval in which the R-phase exists also gradually increased towards lower temperature. For the samples aged between 300 and $400^{\circ} \mathrm{C}$, the transformation temperatures remained fairly constant. It is observed that, in the corresponding ER curves of the specimens, while heating from M-phase, there is a clear R-phase transformation followed by transformation to austenite phase. While cooling from A-phase, transformation to R-phase took place and R-phase remained stable in a larger temperature interval before transforming into martensite phase. In the samples aged above $400^{\circ} \mathrm{C}$, the temperature interval in which the R-phase exists gradually decreased. This decrease is significant for the samples aged above $500^{\circ} \mathrm{C}$ until $600^{\circ} \mathrm{C}$. The ER curves for the samples heat treated between 600 and $900^{\circ} \mathrm{C}$, show the presence of R-phase in the narrow temperature interval and this is a similar behaviour to that of after the first annealing at $900^{\circ} \mathrm{C}$ as observed in Fig. 1(1).

\subsection{Discussion}

As the AR samples are straight annealed ones, subjecting them to heat treatments resulted in an appreciable variation in the transformation behaviour. There is a clear indication that in each alloy, the HTT has an effect on the existence of R-phase.

Generally, due to applied stress during straight annealing, high density of lattice defects is generated. According to Liu et al., the lattice defects and internal stresses can act as negative factors for the movement of martensitic interfaces [7]. When the cold worked material is annealed at higher temperature, thermally activated diffusion and annihilation of lattice defects lead to the release of the stored energy. This reduces the stress barrier for reorientation of lattice planes and promotes martensitic transformation leading to the increase in transformation temperatures with increasing annealing temperature. Accordingly, in Fig. 1(a-d, g \& h) for both alloys, the transformation temperatures appear to gradually increase with the increasing HTT up to $500^{\circ} \mathrm{C}$. For Ti-rich NiTi alloy, the extent of increase in transformation temperatures with the increase in successive HTT is large up to the HTT of $500^{\circ} \mathrm{C}$. This may be attributed to the maximum release of stress and formation of strain free crystals in the matrix due to recrystalisation. The steady increase in transformation temperatures for the samples heat treated above $500^{\circ} \mathrm{C}$ may be associated to the growth of recrystallised grains. Also, the absence of 
R-phase for the samples heat treated in the temperature range from 500 to $900^{\circ} \mathrm{C}$, as seen from the absence of 'cap' in the ER profiles of Fig. 1(e \& f), suggests that there is a considerable decrease of the density of the lattice defects. In the case of Ni-rich NiTi alloy, annealed at a temperature above $500^{\circ} \mathrm{C}$, the ER curves in Fig. 1(i-1) show certain fluctuations in the variation of transformation temperatures. These fluctuations may be attributed to the competing mechanisms, such as release of lattice strain, formation of nucleation sites and precipitation process, vying to dominate over each other. The nucleation sites generated may facilitate the recrystalisation process. Thus, the matrix comprises a dispersion of nucleation sites and clusters of growing strain free micro crystallites. The inter-crystalline regions are in a disordered state and acquire a driving force from annealing process to transform itself into the ordered state [11]. As the starting samples were straight annealed, some preexisting precipitates in the lattice may persist even after ageing at $500^{\circ} \mathrm{C}$, apart from some fresh precipitation taking place during this treatment.
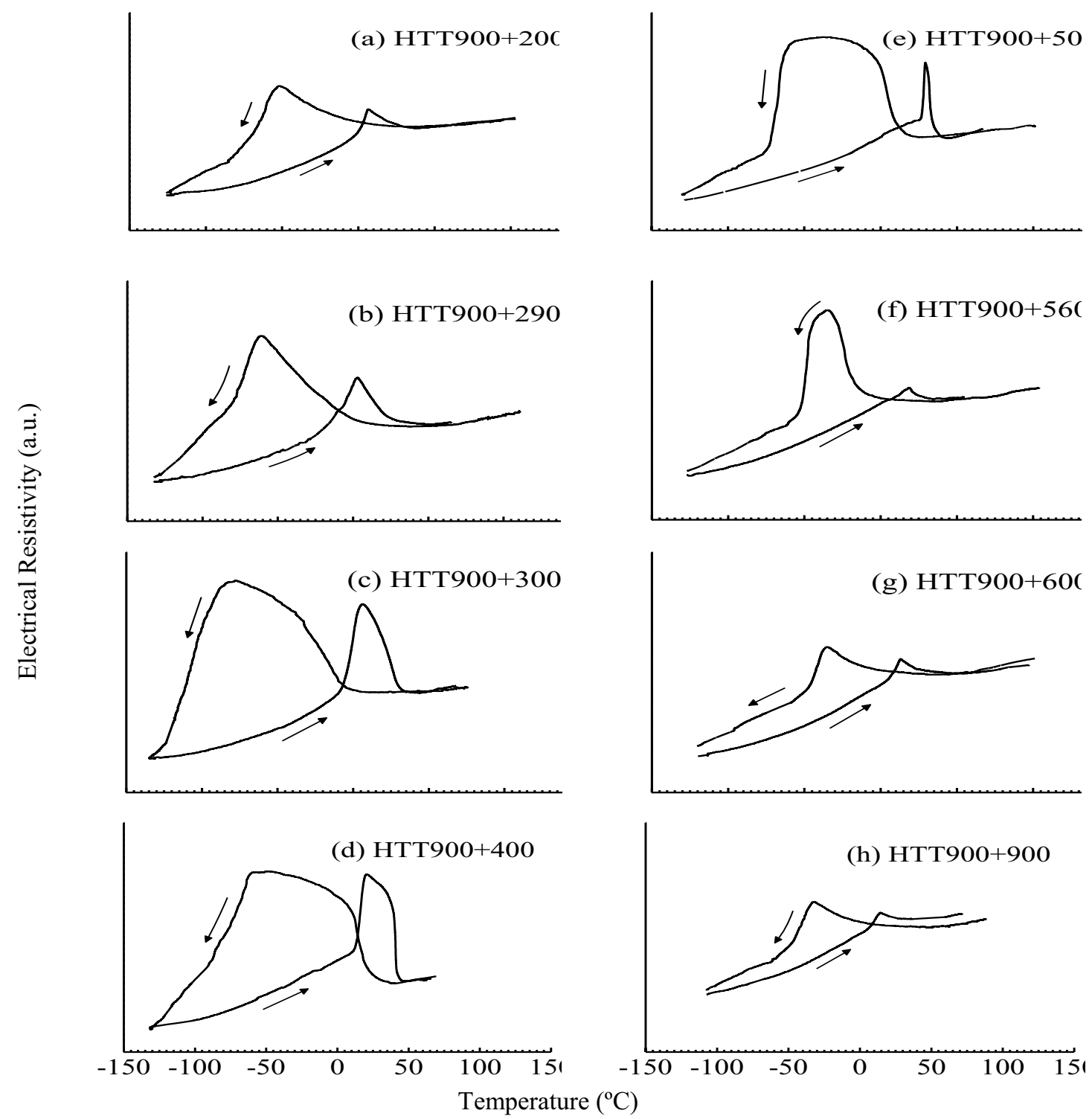

(f) $\mathrm{HTT} 900+56 \mathrm{C}$

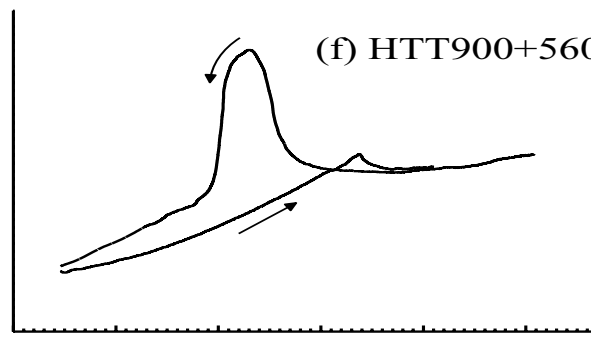

(g) НТТ900+60(

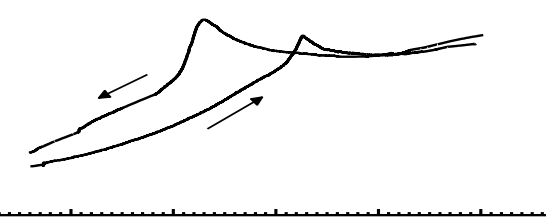

(h) HTT $900+900$

Fig.3: ER curves of the Ni-rich NiTi alloys previously annealed at $900^{\circ} \mathrm{C}$ followed by 2 nd round of heat treatments at (a) 200, (b) 290, (c) 300, (d) 400, (e) 500, (f) 560, (g) 600 and (h) $900^{\circ} \mathrm{C}$.

The presence of a 'cap' in the heating part of the ER profiles of Fig. 1(g-l) of Ni-rich NiTi alloy may be attributed to the presence of intermediate R-phase. In these alloys, the pre-existing precipitates, introduced due to straight annealing and defects introduced due to cold working, may be sufficient for promoting and sustaining Rphase. The decrease in height and width of the temperature range of the 'cap' is an indication that the precipitates get decomposed as the HTT is increased. According to Nishida et al., precipitates of either the metastable $\mathrm{Ni}_{3} \mathrm{Ti}_{2}$ or of the stable $\mathrm{Ni}_{3} \mathrm{Ti}$ are found in $\mathrm{B} 2$ phase for the HTT above $627^{\circ} \mathrm{C}$ [12]. This accounts for the presence of R-phase, even though decaying, when the specimens are annealed above $600^{\circ} \mathrm{C}$. 
ER profiles corresponding to the Ti-rich NiTi alloys in Fig.2, after the second round of heat treatment shows that the samples previously subjected to heat treatment at $900^{\circ} \mathrm{C}$ undergo an irreversible thermal process. Therefore, the following heat treatments do not influence the transformation characteristics. In the case of $\mathrm{Ni}$ rich NiTi alloy, irrespective of the previous thermal treatments, heat treatments in the temperature range from 300 to $560^{\circ} \mathrm{C}$, as observed in Fig. 3(c-f), lead to the presence of R-phase in a significant temperature interval. This effect is mainly attributed to the precipitation of $\mathrm{Ni}_{4} \mathrm{Ti}_{3}$ taking place when the alloy is aged in the above mentioned temperature range [12]. Although $\mathrm{Ni}_{4} \mathrm{Ti}_{3}$ is considered as a metastable phase compared to the equilibrium $\mathrm{Ni}_{3} \mathrm{Ti}$ precipitate, it is quite stable at temperature below $600^{\circ} \mathrm{C}$ and, under normal ageing condition, only $\mathrm{Ni}_{4} \mathrm{Ti}_{3}$ is observed [13]. It is also important to note that in the present study the heat treatment time is 20min., which is suitable for the stability of $\mathrm{Ni}_{4} \mathrm{Ti}_{3}$ precipitates. This precipitate may be responsible in preventing $\mathrm{A} \rightarrow \mathrm{M}$ transformation and also acting as nucleation centres for the formation of R-phase [14].

\section{Conclusion}

In both Ti-rich and Ni-rich NiTi alloys, ER profiles show that there is a clear indication that the HTT has an effect on the existence of R-phase. In the 1st round of heat treatment, the transformation temperatures appear to gradually increase with increasing HTT up to $500^{\circ} \mathrm{C}$. For Ti-rich alloy, the rate of increase in the transformation temperatures with the increase in successive HTT is large up to the HTT of $500^{\circ} \mathrm{C}$ and stabilises for the specimens heat treated above $500^{\circ} \mathrm{C}$.

In the case of Ni-rich alloy, annealed at temperatures above $500^{\circ} \mathrm{C}$, the $\mathrm{ER}$ curves show certain fluctuations in the variation of transformation temperatures. For the HTTs above $600^{\circ} \mathrm{C}$, decay of the R-phase transformation is observed.

After the 2 nd round of heat treatments preceded by the annealing at $900^{\circ} \mathrm{C}$, Ti-rich and Ni-rich $\mathrm{NiTi}$ alloys show different behaviours. ER profiles for the Ti-rich samples only show $\mathrm{M} \leftrightarrow \mathrm{A}$ phase transformations after heat treating at all the temperatures in the tested range. Intermediate R-phase transformation is absent. The observed behaviour is similar to that of the Ti-rich NiTi sample heat treated at $900^{\circ} \mathrm{C}$ during the first round.

ER curves of the Ni-rich NiTi alloys after the 2 nd round of heat treatments (previous annealing at $900^{\circ} \mathrm{C}$ ) show that the sample heat treated at $200^{\circ} \mathrm{C}$ exhibits a similar behaviour to that of after the 1 st heat treatment at $900^{\circ} \mathrm{C}$. Heat treatment in the temperature range from 300 to $560^{\circ} \mathrm{C}$ promotes the effect of ageing, leading to the presence of R-phase transformation, both while heating and cooling. The ER curves for the samples heat treated between $600^{\circ}$ and $900^{\circ} \mathrm{C}$, show the presence of R-phase in a narrow temperature interval. This is a similar behaviour to that after the 1 st heat treatment at $900^{\circ} \mathrm{C}$.

\section{Acknowledgement}

The authors acknowledge FCT/MCTES for the pluriannual financial support of CENIMAT/I3N.

\section{References}

[1] S. Miyazaki, K. Otsuka, ISIJ Intl. 29353 (1989).

[2] J. Uchil, K.P. Mohanachandra, K. Ganesh Kumara, K.K. Mahesh, Mater. Sci. Eng. A 25158 (1998).

[3] Carl P. Frick, Alicia M. Ortega, Jeffrey Tyber, A.El.M. Maksound, Hans J. Maier, Yinong Liu, Ken Gall, Mater. Sci. Eng., A 40534 (2005).

[4] K. Otsuka, X. Ren, T. Takeda, Scr. Mater. 45145 (2001).

[5] Xu Huang, Yong Liu, Scr. Mater 45153 (2001).

[6] T. Saburi, T. Tatsumi, S.Nenno, J de Physique C4 12(43) 261 (1982).

[7] Y. Liu, X. Chen, P.G. McCormick, J. Mat. Sci. 325979 (1997).

[8] H. Sitepu, W.W. Schmahl, J.K. Allafi, G. Eggeler, A. Dlouhy, D.M. Toebbens, M. Tovar, Scr. Mater. 46543 (2002).

[9] J. Uchil, K. Ganesh Kumara, K.K. Mahesh, J. Alloys Compd. 325210 (2001).

[10] J. Uchil, K. Ganesh Kumara, K.K. Mahesh, "Effect of cooling process during heat treatment on martensitic transformation in Ni-Ti and Ni-Ti-Cr alloys", Proc. International Conference on Martensitic

Transformations, ICOMAT'02, Helsinki University of Technology, Espoo, Dipoli, Finland, June 10-14, 2002, edited by J. Pietikäinen and O. Söderberg, J de Physique - IV, France 112 (2003) p.747.

[11] S.H. Avner, Introduction to Physical Metallurgy, 2nd Edn., (Materials Science and Metallurgical Series), Tata McGraw-Hill Publishing Company Ltd., New Delhi, 1997, p.131.

[12] M. Nishida, C.M. Wayman, T. Honma, Met. Trans. 17A 1505 (1986).

[13] J. Zhang, PhD thesis, University of Tsukuba, 2000.

[14] V. Zel'dovich, G. Sobyanina, T.V. Novoselova, J de Physique. 4, 7(5) C5-299 (1997). 